Original Research Paper

\title{
Validation of a Risk Matrix about the Athlete's Oral Health by Analyzing Behavioral and Nutritional Habits
}

\author{
${ }^{1}$ Bárbara Capitanio de Souza, ${ }^{2}$ Randhall Bruce Carteri, ${ }^{3}$ André Luiz Lopes and ${ }^{4}$ Bruno Costa Teixeira \\ ${ }^{1}$ Federal University of Rio Grande do Sul, Dentistry College, Porto Alegre, Brazil \\ ${ }^{2}$ Methodist University Center-Porto Alegre Institute, Nutrition College, Porto Alegre, Brazil \\ ${ }^{3}$ Federal University of Rio Grande do Sul, Physical Education School, Porto Alegre, Brazil \\ ${ }^{4}$ Integrated Regional University of Upper Uruguay and Mission, Physical Education College, São Luiz, Gonzaga, Brazil
}

\section{Article history}

Received: 28-12-2021

Revised: 28-02-2021

Accepted: 11-03-2021

Corresponding Author: Bárbara Capitanio de Souza Federal University of Rio Grande do Sul, Dentistry College, Porto Alegre, Brazil Email: barbara.capitanio@gmail.com

\begin{abstract}
The study proposal was to build a risk matrix on oral health, by analyzing the behavioral and nutritional habits of these individuals and perform your validation. A literature review was carried out to identify risk factors for the oral diseases. The interviewees were 40 volunteer individuals, athletes, professionals or amateurs, or practitioners of physical activity. The validation process consisted of the following steps: 1. Validity of the content; 2. Verbal understanding; 3. Comparison and correlation of the questionnaire test. The Content Validity Coefficients (CVC), the Content Validity Indexes (CVI) and the Kappa correlation coefficients were calculated for each item. In the phase of assessment of verbal comprehension by volunteers, the final CVC for clarity and understanding was 0.869 and 0.854 , respectively. Kappa values varied between 0.5 and 0.667. Cronbach's alpha for each component was calculated, resulting in a cariogenic diet $(\alpha=$ $0.989)$, acid sports drinks $(\alpha=0.964)$, oral hygiene $(\alpha=0.963)$ and dental services $(\alpha=0.980)$. The definition of this oral profile, in conjunction with an athlete's individual needs, can define treatment and prevention programs, including education in oral health.
\end{abstract}

Keywords: Dentistry, Dental Clinics, Athletes, Oral Health

\section{Introduction}

Regular sports practice is related to better physical results and decreased major mortality risk factors. In addition, sports engagement is related to better health outcomes and increased life expectancy (Frese et al., 2018). Conversely, oral heath became a rising concern to amateur and professional athletes, as there seems to be a consensus that most athletes have poor oral health, similarly to people with low socioeconomic status (Needleman et al., 2014).

Dental problems can be detrimental to sports performance, especially in athletes with an intense training routine and who perform frequently. In addition to situations involving severe pain or discomfort compatible with acute infections, the athlete is also subject to chronic infectious-inflammatory diseases of periodontal tissues, dental fractures due to trauma, orofacial fractures, loss of tooth structure due to chemical erosion, cavities and temporomandibular joint disorders (Ashley et al., 2015). These conditions may directly interfere in training adaptation, such as the case of infectious-inflammatory diseases and pain. Thus, an athlete's oral health condition must be considered as a potential impact factor for the success of training and competitions (Needleman et al., 2014).

Dietary and behavioral habits are among the main risk factors associated with oral health problems in athletes, whereas the most prevalent oral diseases are dental caries and periodontitis, which present different etiology (Touger-Decker and van Loveren, 2003). Therefore, considering the particularities that comprise an athlete's routine and lifestyle to reach specific goals in sports practice, it is important to establish clinical care protocols able to detect specific individual characteristics that may influence oral health, while also ensuring appropriate nutritional support. Thus, the objective of the study was to review the literature on athletes' oral health problems, propose a risk matrix on oral health, by analyzing the behavioral and nutritional habits of these individuals and perform your validation. This tool can be used as an aid in patient's risk diagnosis and improve the choice of specific treatments. 


\section{Methods}

\section{Ethical Considerations}

The project was approved by the Human Research Ethics Committee. Participants were informed about all stages of the research, the recognition of the minimum risks to the volunteer's health, the option to withdraw from participating in the study at any time, as well as the confidentiality of personal data. The volunteers signed an Informed Consent, as determined by the current legislation. This research is in line with Resolution 466/12 of the National Health Council and the Declaration of Helsinki.

\section{Sample}

The sample was composed of two distinct groups: Evaluators and interviewees. The evaluators were 3 dental surgeons invited voluntarily, who were trained and instructed on the operation and application of risk matrices. The interviewees were 40 volunteer individuals, athletes, professionals or amateurs, or practitioners of physical activity. The sample was calculated using the EPI Info software version 7.2 (EPI Info, Center for Disease Control, Atlanta, Georgia, 2017), based on a linear correlation coefficient of 0.947 (Table 1), which resulted from the responses obtained by two evaluators (senior evaluator and test evaluator), through a pre-evaluation $(\mathrm{N}=5)$, with a $95 \%$ confidence interval, probability of type I error $(\alpha)$ of $5 \%$ and test power of $80 \%$. $10 \%$ were included as an estimate of sample loss. All interviews, instructions and evaluations were carried out in the senior appraiser's office, at pre-defined times with the participants.

\section{Construction of Risk Matrices}

Initially, a search was performed in the PubMed database between January and February 2020. There was no restriction on the year of publication. The search for articles was carried out using the following combinations of terms: Nutrition, athlete, oral health, caries, dental erosion, periodontal disease, oral hygiene. After an analysis of the title and the available abstract, articles that did not deal with the proposed topic, that were not published in English, or that did not provide the full text were excluded. The search was conducted considering the relationship between nutrition and oral health problems. Studies approaching Paralympic sports were not included, due to specific interfering factors such as motor skills and pharmacological agents prescription. At the end of the analysis, 36 papers were selected for reading and to assist in the construction of risk matrices. Table 2 indicates the issues related to the outcomes of the main oral diseases, indicating the selected risk factor, component, domain, construct and category for the construction of the instrument.
Risk matrices are management tools used to measure the risk of certain events occurring, enabling qualitative risk classification and assists in planning individualized actions. Thus, this ensures better intervention for each case, according to the athlete's profile and routine. For the construction of qualitative risk analysis matrices, several risk factors for oral diseases with a significant impact for athletes were used: Cariogenic diet, intake of acidic drinks, oral hygiene habits and access to dental services. Each factor was scaled, individually, according to its degree and risk. The established risks are based on data already known from the literature, for oral diseases (Olczak-Kowalczyk et al., 2016; Head et al., 2017; Hong et al., 2018; Obregón-Rodríguez et al., 2019; Baishya et al., 2019). The results resulted in scores that were converted into recommendations in a scoring matrix. Risk matrices were constructed following the sequence shown in.

The characterization of oral diseases in the athlete was based on literature prevalence data that indicate that the proportion of athletes affected by these conditions were dental caries (15-75\%), moderate-to-severe periodontitis (up to 15\%) and dental erosion (36-85\%) (Needleman et al., 2014; Ashley et al., 2015). The disease incidence was generally not clearly differentiated by socioeconomic status; however, poor oral health appears to affect athletes, regardless of the country of origin. Needleman et al. (2014) Oral health has risk factors that are associated with health behaviors such as beliefs, education, access to preventive programs and personal care. We do not have many studies that address these factors in sport, but we know that awareness of the risk of oral disease is low among athletes, increasing the prevalence of these conditions (Needleman et al., 2014; Frese et al., 2018).

Oral health has consistently been shown to be poor with a high treatment need for athletes. This may be associated with risk factors for oral diseases, which are present in the athlete's routine, especially oral hygiene after eating and using foods with high carbohydrate content frequently. These are nutritional challenges from frequent carbohydrate intake and acidic sports drinks and poor health behaviors and lack of health promotion and preventive support (Needleman et al., 2014). For this reason, factors such as hygiene habits and access to health services were included in the construction of the risk matrix.

\section{Validation of the Risk Matrix}

The validation process consisted of the following steps: 1 . the validity of the content between the judges; 2. Verbal understanding of volunteers; 3. Comparison and correlation of the questionnaire test. To validate the content, considering clarity and relevance, three experienced dentistry professors were invited to form a committee, which evaluated the questions built by each 
matrix. This evaluation was carried out with the aid of a Likert scale, graded from 1 to 5 with the following denominations: Very nuclear, not overly clear, nuclear, clear and very clear, for the criterion of clarity and very irrelevant, not overly relevant, irrelevant, relevant and very relevant, for relevance. After the evaluations, the Content Validity Coefficients (CVC), the Content Validity Indexes (CVI) and the Kappa correlation coefficients were calculated for each item (Table 3). Adjustment needs were made before the analysis of verbal comprehension.

The verbal comprehension stage of the volunteers was carried out with a preliminary study, considering clarity and understanding. This evaluation counted with the participation of 10 interviewees, who analyzed each item of the matrix with the aid of a Likert scale, graded from 1 to 5 with the following denominations: Very nuclear, not overly clear, nuclear, clear and very clear, for the criterion of clarity and very misunderstood, not very understood, misunderstood, understood, very understood, for understanding. After the evaluations, the Content
Validity Coefficients (CVC), the Content Validity Indexes (CVI) and the Kappa correlation coefficients were also calculated for each item (Table 4). The volunteers pointed out the main doubts regarding the instructions, questions and answer options, or any other aspect that was confused during the application of the matrices.

The final stage of the validation of risk matrices was carried out with the participation of three evaluators, dental surgeons and 40 respondents. These participants were randomly selected in three groups. Each group was interviewed by 1 different evaluator, with an interval of at least one week, until all evaluators applied the risk matrices to all participants. Before the beginning of the interviews, the senior evaluator performed a previous data collection, for later comparison. Analyzes were performed using the mean and standard deviation of responses and the linear correlation coefficient between the senior appraiser and the other appraisers. Also, Cronbach's alpha was calculated for each component, to estimate the confidence of the responses of the instrument or its domain (Table 5).

Table 1: Comparison and correlation of the questionnaire pre-evaluation

\begin{tabular}{llll}
\hline & Senior evaluator & Test evaluator & \\
Risk Matrix criteria & Mean \pm SD & Mean \pm SD & CC \\
\hline Cariogenic diet & $2.4 \pm 1.140$ & $2.4 \pm 1.140$ & 1.000 \\
Acid sports drinks & $2 \pm 0.707$ & $1.6 \pm 0.894$ & 0.790 \\
Oral hygiene & $2 \pm 0.707$ & $2 \pm 0.707$ & 1.000 \\
Dental services & $2 \pm 1.224$ & $2 \pm 1.224$ & 1.000 \\
& & CC & 0.947 \\
\hline
\end{tabular}

CC: Linear Correlation Coefficient. $\mathrm{N}=5$. Interpretation of CC: 0-0.3: Negligible correlation; 0.31-0.5: Weak correlation; 0.51-0.7: Moderate correlation; 0.71-0.9: Strong correlation; >0.9: Very strong correlation (Mukaka, 2012)

Table 2: Issues related to the risk outcomes of the main oral diseases, based on dietary and behavioral habits

\begin{tabular}{|c|c|c|c|c|c|}
\hline Matrix & Risk factor & Component & Domain & Construct & Category \\
\hline 1 & Cariogenic diet & $\begin{array}{l}\text { Ingestion } \\
\text { of cariogenic foods }\end{array}$ & $\begin{array}{l}\text { Quantity and frequency of } \\
\text { consumption of cariogenic foods }\end{array}$ & $\begin{array}{l}\text { Phasic demineralization and } \\
\text { remineralisation of dental } \\
\text { hard tissues }\end{array}$ & Dietary habit \\
\hline 3 & Oral hygiene & Oral hygiene habits & Quality and frequency of oral hygiene & Biofilm control & Behavioral habit \\
\hline 4 & Dental services & Access to dental care & Frequency of access to dental care and need & Oral health & Behavioral habit \\
\hline
\end{tabular}

Table 3: Content validity among the judges

\begin{tabular}{|c|c|c|c|c|c|c|c|c|c|c|c|c|c|c|}
\hline & \multicolumn{7}{|l|}{ Clarity } & \multicolumn{7}{|l|}{ Relevance } \\
\hline & Agreement & Kappa & CVI & Mean & $\mathrm{CVC}_{\mathrm{i}}$ & $\mathrm{Pe}$ & $\mathrm{CVC}_{\mathrm{f}}$ & Agreement & Kappa & CVI & Mean & $\mathrm{CVC}_{\mathrm{i}}$ & $\mathrm{Pe}$ & $\mathrm{CVC}_{\mathrm{f}}$ \\
\hline $\begin{array}{l}\text { Question } 1 \text { - frequency of } \\
\text { consumption of cariogenic food. }\end{array}$ & $100 \%$ & 1.0 & 1 & 4.00 & 0.80 & 0.037 & 0.763 & $66.6 \%$ & 0.5 & 1 & 4.66 & 0.93 & 0.037 & 0.893 \\
\hline $\begin{array}{l}\text { consumption of acidic drinks. } \\
\text { Question } 3 \text { - Frequency of }\end{array}$ & $66.6 \%$ & 0.5 & 1 & 4.33 & 0.86 & 0.037 & 0.823 & $100 \%$ & 1.0 & 1 & 5.00 & 1.00 & 0.037 & 0.963 \\
\hline oral hygiene. & $100 \%$ & 1.0 & 1 & 4.00 & 0.80 & 0.037 & 0.763 & $66.6 \%$ & 0.5 & 1 & 4.66 & 0.93 & 0.037 & 0.893 \\
\hline
\end{tabular}

services per year.

CVCi: Initial Content Validity Coefficient for each item; Pe: Error; CVCf: Finale Content Validity Coefficient; CVCt: Total Content Validity Coefficient; CVI: Content Validity Index; Kappa: Kappa correlation coefficient. N = 3. Classification of the level of agreement by the Kappa coefficient: <0 there is no agreement; 0-0.2: Minimal agreement; 0.21-0.4: Reasonable agreement; 0.41-0.6: Moderate agreement; 0.61-0.8: Substantial agreement; 0.81-1.0: Perfect agreement (Landis and Koch, 1977). The cut-off point adopted to determine satisfactory levels for language clarity and relevance was $\mathrm{CVCf} \geq 0.70$ for each item and $\mathrm{CVCt} \geq 0.70$ for the instrument in general (Cassepp-Borges et al., 2010) 


\begin{tabular}{|c|c|c|c|c|c|c|c|c|c|c|c|c|c|c|}
\hline & \multicolumn{7}{|l|}{ Clarity } & \multicolumn{7}{|c|}{ Understanding } \\
\hline & Agreement & Kappa & CVI & Mean & $\mathrm{CVC}_{\mathrm{i}}$ & $\mathrm{Pe}$ & $\mathrm{CVC}_{\mathrm{f}}$ & Agreement & Kappa & CVI & Mean & $\mathrm{CVC}_{\mathrm{i}}$ & $\mathrm{Pe}$ & $\mathrm{CVC}_{\mathrm{f}}$ \\
\hline $\begin{array}{l}\text { Question } 1 \text { - Frequency of } \\
\text { consumption of cariogenic food. }\end{array}$ & $80 \%$ & 0.667 & 0.9 & 4 & 0.80 & $10^{-10}$ & 0.799 & $80 \%$ & 0.667 & 1.0 & 4.2 & 0.84 & $10^{-10}$ & 0.839 \\
\hline $\begin{array}{l}\text { Question } 2 \text { - Frequency of } \\
\text { consumption of acidic drinks. }\end{array}$ & $70 \%$ & 0.500 & 1 & 4.3 & 0.86 & $10^{-10}$ & 0.859 & $70 \%$ & 0.500 & 1.0 & 4.7 & 0.94 & $10^{-10}$ & 0.939 \\
\hline $\begin{array}{l}\text { Question } 3 \text { - Frequency of } \\
\text { oral hygiene. }\end{array}$ & $70 \%$ & 0.500 & 1 & 4.3 & 0.86 & $10^{-10}$ & 0.859 & $80 \%$ & 0.667 & 1.0 & 4.2 & 0.84 & $10^{-10}$ & 0.839 \\
\hline $\begin{array}{l}\text { Question } 4 \text { - Frequency of } \\
\text { possibility of using dental }\end{array}$ & $80 \%$ & 0.667 & $\begin{array}{l}1 \\
\mathrm{CVC}\end{array}$ & $\begin{array}{r}4.8 \\
\text { clarity }\end{array}$ & 0.96 & $10^{-10}$ & $\begin{array}{l}0.959 \\
0.869\end{array}$ & $80 \%$ & 0.667 & $\begin{array}{l}0.9 \\
\text { CVC }\end{array}$ & $\begin{array}{l}4.0 \\
\text { nderstandin }\end{array}$ & 0.80 & $10^{-10}$ & $\begin{array}{l}0.799 \\
0.854\end{array}$ \\
\hline
\end{tabular}

services per year.

CVCi: Initial Content Validity Coefficient for each item; Pe: Error; CVCf: Finale Content Validity Coefficient; CVCt: Total Content Validity Coefficient; CVI: Content Validity Index; Kappa: Kappa correlation coefficient. $\mathrm{N}=10$. Classification of the level of agreement by the Kappa coefficient: $<0$ there is no agreement; $0-0.2$ : Minimal agreement; 0.21-0.4: Reasonable agreement; 0.41-0.6: Moderate ag reement; 0.61-0.8: Substantial agreement; 0.81-1.0: Perfect agreement (Landis and Koch, 1977). The cut-off point adopted to determine satisfactory levels for language clarity and relevance was $\mathrm{CVCf} \geq 0.70$ for each item and $\mathrm{CVCt} \geq 0.70$ for the instrument in general (Cassepp-Borges et al., 2010)

Table 5: Comparison and correlation of the questionnaire test

\begin{tabular}{|c|c|c|c|c|c|c|c|c|}
\hline \multirow[b]{2}{*}{ Risk Matrix criteria } & \multirow{2}{*}{$\begin{array}{l}\text { Senior evaluator } \\
\text { Mean } \pm \text { SD }\end{array}$} & \multicolumn{2}{|c|}{ Evaluator 1} & \multicolumn{2}{|c|}{ Evaluator 2} & \multicolumn{2}{|c|}{ Evaluator 3} & \multirow[b]{2}{*}{ Cronbach's alpha } \\
\hline & & $\mathrm{CC}$ & Mean \pm SD & $\mathrm{CC}$ & Mean \pm SD & $\mathrm{CC}$ & Mean \pm SD & \\
\hline Cariogenic Diet & $2 \pm 0.694$ & 1.000 & $2 \pm 0.694$ & 0.964 & $2.033 \pm 0.668$ & 0.967 & $1.966 \pm 0.718$ & 0.989 \\
\hline Acid Sports Drinks & $1.9 \pm 0.758$ & 1.000 & $1.9 \pm 0.758$ & 0.949 & $1.966 \pm 0.808$ & 0.876 & $1.966 \pm 0.668$ & 0.964 \\
\hline Oral Hygiene & $2.2 \pm 0.714$ & 0.939 & $2.266 \pm 0.739$ & 0.939 & $2.266 \pm 0.739$ & 0.865 & $2.266 \pm 0.691$ & 0.963 \\
\hline Dental Services & $2.666 \pm 0.922$ & 0.959 & $2.666 \pm 0.922$ & 0.943 & $2.766 \pm 0.858$ & 0.980 & $2.633 \pm 0.927$ & 0.980 \\
\hline
\end{tabular}

CC: Linear Correlation Coefficient in relation to the senior evaluator. $\mathrm{N}=38$. Interpretation of CC: 0-0.3: Negligible correlation; 0.31-0.5: Weak correlation; 0.51-0.7: Moderate correlation; 0.71-0.9: Strong correlation; >0.9: Very strong correlation (Mukaka, 2012). Cronbach's alpha reliability: Very low $(\alpha \leq 0.30)$; low $(0.30<\alpha<0.60)$; moderate $(0.60<\alpha<0.75)$; high $(0.75<\alpha \leq 0.90)$ and very high $(\alpha>0.90)$ (Gottems et al., 2018)

\section{Analysis}

All resulting data were tabulated for the analysis. Microsoft Excel® version 2010 software (Microsoft Corp) was used for calculating the linear Correlation Coefficients (CC), Content Validity Coefficients (CVC), Content Validity Indexes (CVI), Kappa correlation coefficients and Cronbach's alpha (Divisi et al., 2017).

\section{Results}

The instrument consisted of four components that vary in their domain concerning quantity and frequency, quality and frequency and access and need and its realization is very succinct. Individual risk matrices were prepared, according to the cariogenic diet (Fig. 1), acid drink intake (Fig. 2), oral hygiene habits (Fig. 3) and access to dental services (Fig. 4). The individual evaluation with the aid of each matrix results in a score indicated in Fig. 5, followed by its orientation.

During the content validity phase, the teacher's committee members suggested the inclusion of a brief initial explanation, with instructions on how to apply the risk matrix (figure's description). There was also a suggestion to replace the expression "low-sticky foods" with "foods with little adherence", used in the matrix corresponding to the risk factor, cariogenic diet. The final CVC for clarity and relevance was 0.778 and 0.893 , respectively. The cut-off point adopted to determine satisfaction levels for this assessment was $\mathrm{CVC} \geq 0.70$.
Kappa values varied between 0.5 and 1, indicating a moderate to perfect agreement (Table 3).

In the phase of assessment of verbal comprehension by volunteers, there was no need for clarification and, therefore, the matrix did not need to be reassessed. In this step, the final CVC for clarity and understanding was 0.869 and 0.854 , respectively. The cut-off point adopted to determine satisfaction levels for this assessment was also $\mathrm{CVC} \geq 0.70$. Kappa values varied between 0.5 and 0.667 , indicating a moderate to the substantial agreement (Table 4).

The comparison and correlation of the questionnaire test, carried out in the third phase of validation, had the participation of $38(30.4 \pm 7.11$ age $)$ interviewees. Two participants did not complete the interviews, however, the sample calculation was performed with an estimate of losses and this fact had no significant impact on the results. This stage of the analysis showed reliability in the reproduction of the interviews between the evaluators over the evaluation weeks. The linear Correlation Coefficient (CC), analyzed by the senior appraiser, varied between 0.865 and 1 , indicating a moderate to very strong correlation agreement and also suggesting good temporal stability or external reliability. Cronbach's alpha for each component was calculated as a measure of internal consistency or reliability among the evaluators, resulting in the cariogenic diet $(\alpha=0.989)$, acid sports drinks $(\alpha=0.964)$, oral hygiene $(\alpha=0.963)$ and dental services $(\alpha=0.980)$ (Table 5). 


\section{Discussion}

The studies show that increased intake of cariogenic foods, sports nutrition products and sports drinks can contribute to the increased risk of oral problems such as dental erosion, caries and periodontal conditions; especially when accompanied by poor hygiene or restricted access to dental services. Based on this, this study created and validated a risk identification method for the oral health of the athlete patient, considering the most prevalent dental diseases in this population. Besides, the developed risk matrix may also serve as a research tool and for standardizing the clinical assessments performed.

Athletes are exposed to several different risk factors for oral diseases. Considering specific nutritional particularities, this population is susceptible to an important cariogenic challenge, since the consumption of a diet rich in carbohydrates and sugars is frequent, especially in the form of pastes and gels (Gallagher et al., 2019). A plethora of evidence indicates that the effects of a cariogenic diet in overall health may not be counterbalanced by the protective induced by the use of fluorides (Broad and Rye, 2015; Frese et al., 2018).

The cariogenic potential associated with sports nutrition practices during specific training periods or throughout competitions affects the oral flora, significantly affecting the quality and quantities of specific microorganisms. For example, Streptococcus spp, the main bacterium associated with the appearance of carious lesions, is abundantly present in the oral flora of athletes (Minty et al., 2018; Murtaza et al., 2019). Ultimately, these detrimental effects on oral health could compromise sports performance (Murtaza et al., 2019).

Therefore, to ensure sports performance while minimizing potential risks, integrating information regarding dental health with a balanced and healthy nutritional orientation is vital (Studen-Pavlovich et al., 2000; Needleman et al., 2018). Thus, based on the nutritional characteristics of the athletes and the risk factors for oral diseases, especially dental caries, a risk matrix for a cariogenic diet in sports nutrition was built Fig. 1, which assesses the risk of the disease according to frequency and intake of cariogenic foods. The purpose of this matrix was to establish guidance on the patient's risk level, according to specific criteria, allowing the dentist to carry out individualized clinical planning.

Current literature indicates that athletes have worse oral health and this may be associated with their behavioral and dietary peculiarities, which could lead to decreased performance associated with a cariogenic diet (Azodo and Osazuwa, 2013; Ostrowska et al., 2016). The second risk matrix considers the frequency of sports drinks consumption, (which are acidic drinks) and specific precautions following consumption Fig. 2. This practice is quite common in sports, particularly among athletes who do not usually perform appropriate nutritional monitoring. Although there are specific recommendations for the use of this type of drink, the commercial appeal is still a factor influencing nutrition choices in this population (Morgan et al., 2016).

Ingestion of these drinks has cariogenic potential, associated with a reduction of the $\mathrm{pH}$ of the oral environment, demineralizing dental tissues and increasing the process of chemical erosion (Coombes, 2005). Sports drinks were developed to improve hydration and performance of athletes, albeit containing relatively high amounts of sugars, salt and citric acid, which are risk factors for poor oral health (Mathew et al., 2002; Noble et al., 2011). The frequent consumption of these products associated with poor oral health practices is common in athletes (Sirimaharaj et al., 2002).

Oral hygiene is an important risk factor for diseases of the oral cavity, which is directly related to individual perception of health and behavioral habits (Anttonen et al., 2014). It is well described that athletes often present poor oral health condition associated with poor oral hygiene, which potentiates the risks for oral diseases associated with specific dietary habits since we can observe a significant prevalence of periodontal diseases, which can have an impact on sports performance, as already reported (Gallagher et al., 2018). The biofilm is the primary etiologic agent in periodontal diseases. These are one of the most common chronic inflammatory diseases in the world and there is emerging interest in the link between oral health and other clinics condition (Lönn et al., 2018).

Appropriate oral health is vital to overall health and quality of life, while also influencing several factors which could be responsible for the appearance of several diseases, including systemic inflammatory responses and impaired muscle metabolism (Cullinan and Seymour, 2013; de Souza et al., 2020). Thus, oral hygiene is fundamental for decreasing the development of dental pathologies and possible complications that can compromise the athlete. Figure 3 presents the risk matrix for oral hygiene and also associates exposure to fluorides. The control of plaque and access to fluoride is the most expressive methods for maintaining dental structure (Frese et al., 2018).

It should be noted that in all the risk factors mentioned above, they may increase the systemic inflammation of the athlete. Inflammatory mediators such as Tumor Necrosis Factor-alpha (TNF $\alpha$ ) and Interleukin-6 (IL-6) are important mediators of catabolic responses such as muscle protein loss and consequently, in performance reduce (Durham et al., 2009). Inflammation, which is characterized by increases in macrophage infiltration and levels of inflammatory cytokines/chemokines (e.g., TNF $\alpha$; 
Monocyte Chemoattractant Protein 1, MCP-1), is associated with this muscle atrophy (Valerio et al., 2006; Varma et al., 2009).

After the initial analysis using the previous matrices, it is possible to establish a risk score for oral diseases, estimating basic care guidelines Fig. 5. Since athletes are at potential risk due to their routines, an appropriate assessment of oral health may reduce the risk of oral pain, inflammation and infection and, thus, minimizing the use of medications or days of departure from training (Bryant et al., 2011; Needleman et al., 2013; Frese et al., 2015).

\begin{tabular}{|c|c|c|c|c|c|c|}
\hline \multirow{2}{*}{\multicolumn{3}{|c|}{ Cariogenic diet }} & \multicolumn{4}{|c|}{ Amount of food intake with high sugar content: } \\
\hline & & & Low & Moderate & High & Very high \\
\hline \multirow{4}{*}{$\begin{array}{l}\text { Frequency of } \\
\text { consumption of } \\
\text { cariogenic food. } \\
\text { (days/week) }\end{array}$} & & $\leq 1$ & Low $=1$ & Low $=1$ & High $=3$ & High $=3$ \\
\hline & & 2 & Low $=1$ & Moderate $=2$ & High $=3$ & Very high $=4$ \\
\hline & & $3-4$ & Low $=1$ & Moderate $=2$ & High $=3$ & Very high $=4$ \\
\hline & & $>4$ & Moderate $=2$ & Moderate $=2$ & Very high $=4$ & Very high $=4$ \\
\hline \multicolumn{7}{|c|}{ Risk for oral diseases and description of factors } \\
\hline Low & \multicolumn{6}{|c|}{$\begin{array}{l}\text { Ingestion of solid food, following WHO recommendations, not exceeding } 10 \% \text { of the daily } \\
\text { energy consumption, or } 50 \mathrm{~g} \text { per day. }\end{array}$} \\
\hline Moderate & \multicolumn{6}{|c|}{$\begin{array}{l}\text { Ingestion of foods with little teeth adherence, exceeding } 10 \% \text { of the daily energy consumption, } \\
\text { or up to } 100 \mathrm{~g} \text { per day. }\end{array}$} \\
\hline High & \multicolumn{6}{|c|}{$\begin{array}{l}\text { Ingestion of foods with moderate teeth adherence, exceeding } 10 \% \text { of the daily energy consumption, } \\
\text { or up to } 100 \mathrm{~g} \text { per day. }\end{array}$} \\
\hline Very high & \multicolumn{6}{|c|}{$\begin{array}{l}\text { Ingestion of foods with moderate and high teeth adherence, exceeding } 10 \% \text { of the daily energy } \\
\text { consumption and above } 100 \mathrm{~g} \text { per day. }\end{array}$} \\
\hline
\end{tabular}

Fig. 1: Risk Matrix for cariogenic diet in sports nutrition. To use this matrix, one should first ask the weekly frequency of consumption of cariogenic foods (sweets, candies, chocolates, stuffed cookies, chocolates, homemade sweets, desserts and the like, sugared drinks, soft drinks). This information must be marked according to the indication of each line $(\leq 1,2,3-4$ and $>4)$. Then, the average frequency of cariogenic food consumption based on sugar content (50 g per day, up to $100 \mathrm{~g}$ per day and above $100 \mathrm{~g}$ per day) should be estimated. This information will indicate the corresponding column

\begin{tabular}{|c|c|c|c|c|c|c|}
\hline \multirow{2}{*}{\multicolumn{3}{|c|}{ Acid sports drinks }} & \multicolumn{4}{|c|}{ Supervision, care and intake of drinks with low $\mathrm{pH}$} \\
\hline & & & Low & Moderate & High & Very high \\
\hline \multirow{5}{*}{$\begin{array}{l}\text { Frequency of } \\
\text { consumption of } \\
\text { acidic drinks. } \\
\text { (days/week) }\end{array}$} & & $\leq 1$ & Low $=1$ & Low $=1$ & High $=3$ & High $=3$ \\
\hline & & 2 & Low $=1$ & Moderate $=2$ & High $=3$ & Very high $=4$ \\
\hline & & $3-4$ & Low $=1$ & Moderate $=2$ & High $=3$ & Very high $=4$ \\
\hline & & $>4$ & Moderate $=2$ & Moderate $=2$ & Very high $=4$ & Very high $=4$ \\
\hline & & \multicolumn{5}{|c|}{ Risk for oral diseases and description of factors } \\
\hline Low & \multicolumn{6}{|c|}{ Rare intake of acid drinks of intake followed by mouth rinse after consumption. } \\
\hline Moderate & \multicolumn{6}{|c|}{$\begin{array}{l}\text { Consumption under nutritional supervision and usually rinses the mouth after consumption } \\
\text { (not immediately). }\end{array}$} \\
\hline High & \multicolumn{6}{|c|}{$\begin{array}{l}\text { Consumption without nutritional supervision but usually rinses the mouth after consumption } \\
\text { (not immediately). }\end{array}$} \\
\hline Very high & \multicolumn{6}{|c|}{$\begin{array}{l}\text { Consumption without nutritional supervision and without washing the mouth after consumption } \\
\text { (not immediately). }\end{array}$} \\
\hline
\end{tabular}

Fig. 2: Risk Matrix for sports drinks. To use this matrix, one should first ask the weekly frequency of consumption of sports drinks (repositories, isotonic, hypertonic and hypotonic drinks). This information must be marked according to the indication of each line ( $\leq 1,2,3-4$ and $>4$ ). Then, risk-related conduct must be marked (if this consumption is being prescribed by the nutritionist and if the individual performs a mouth rinse after ingestion). This information will indicate the corresponding column 


\begin{tabular}{|c|c|c|c|c|c|c|}
\hline \multirow{2}{*}{\multicolumn{3}{|c|}{ Oral hygiene }} & \multicolumn{4}{|c|}{ Oral hygiene conditions and methods } \\
\hline & & & Low & Moderate & High & Very high \\
\hline \multirow{4}{*}{$\begin{array}{l}\text { Frequency of } \\
\text { oral hygiene. } \\
\text { (daily) }\end{array}$} & & $>4$ & Low $=1$ & Low $=1$ & High $=3$ & High $=3$ \\
\hline & & $3-4$ & Low $=1$ & Moderate $=2$ & High $=3$ & Very high $=4$ \\
\hline & & 2 & Low $=1$ & Moderate $=2$ & High $=3$ & Very high $=4$ \\
\hline & & $\leq 1$ & Moderate $=2$ & Moderate $=2$ & Very high $=4$ & Very high $=4$ \\
\hline \multicolumn{7}{|c|}{ Risk for oral diseases and description of factors } \\
\hline Low & \multicolumn{6}{|c|}{$\begin{array}{l}\text { Performing oral hygiene following meals, using toothbrush and fluoride toothpaste. Daily flossing and access to } \\
\text { fluoridated water. }\end{array}$} \\
\hline Moderate & \multicolumn{6}{|c|}{$\begin{array}{l}\text { Not performing oral hygiene following every meal, but uses a toothbrush and fluoride toothpaste. Flossing every } \\
\text { other day and access to fluoridated water. }\end{array}$} \\
\hline High & \multicolumn{6}{|c|}{$\begin{array}{l}\text { Not performing oral hygiene following every meal, but uses a toothbrush and fluoride toothpaste. Not flossing and } \\
\text { without access to fluoridated water. }\end{array}$} \\
\hline Very high & \multicolumn{6}{|c|}{ Failure to perform oral hygiene after all meals and without access to fluorine. } \\
\hline
\end{tabular}

Fig. 3: Risk Matrix for oral hygiene. To use this matrix, one must first ask what is the daily frequency of oral hygiene performed. This information must be marked according to the indication of each line $(>4,3-4,2, \leq 1)$. Then, hygiene procedures (after meals, using a brush and fluoride toothpaste, dental floss and if the individual has access to fluoridated water) should be marked. This information will indicate the corresponding column

\begin{tabular}{|c|c|c|c|c|c|c|}
\hline \multirow{2}{*}{\multicolumn{3}{|c|}{ Dental services }} & \multicolumn{4}{|c|}{ Access to dental services and treatments } \\
\hline & & & Low & Moderate & High & Very high \\
\hline \multirow{4}{*}{\multicolumn{2}{|c|}{$\begin{array}{l}\text { Frequency of possibility } \\
\text { of using dental services. } \\
\text { (yearly) }\end{array}$}} & $>4$ & Low $=1$ & Low $=1$ & High $=3$ & High $=3$ \\
\hline & & $3-4$ & Low $=1$ & Moderate $=2$ & High $=3$ & Very high $=4$ \\
\hline & & 2 & Low $=1$ & Moderate $=2$ & High $=3$ & Very high $=4$ \\
\hline & & $\leq 1$ & Moderate $=2$ & Moderate $=2$ & Very high $=4$ & Very high $=4$ \\
\hline \multicolumn{7}{|c|}{ Risk for oral diseases and description of factors } \\
\hline Low & \multicolumn{6}{|c|}{ Full access to dental services and treatments and often uses it, even without an apparent need. } \\
\hline Moderate & \multicolumn{6}{|c|}{ Full access to dental services and treatment, but uses it only with the need or in an emergency situation due to pain. } \\
\hline High & \multicolumn{6}{|c|}{ Full access to dental services and treatment, but without using it, even with apparent need. } \\
\hline Very high & \multicolumn{6}{|c|}{ Restricted access to dental services and treatments. } \\
\hline
\end{tabular}

Fig. 4: Risk matrix for dental services. To use this matrix, one must first ask how often to access dental services annually. This information must be marked according to the indication of each line $(>4,3-4,2, \leq 1)$. Then, one should ask in what situation does the individual seek this service (periodic reviews, elective treatments, emergencies). This information will indicate the corresponding column 


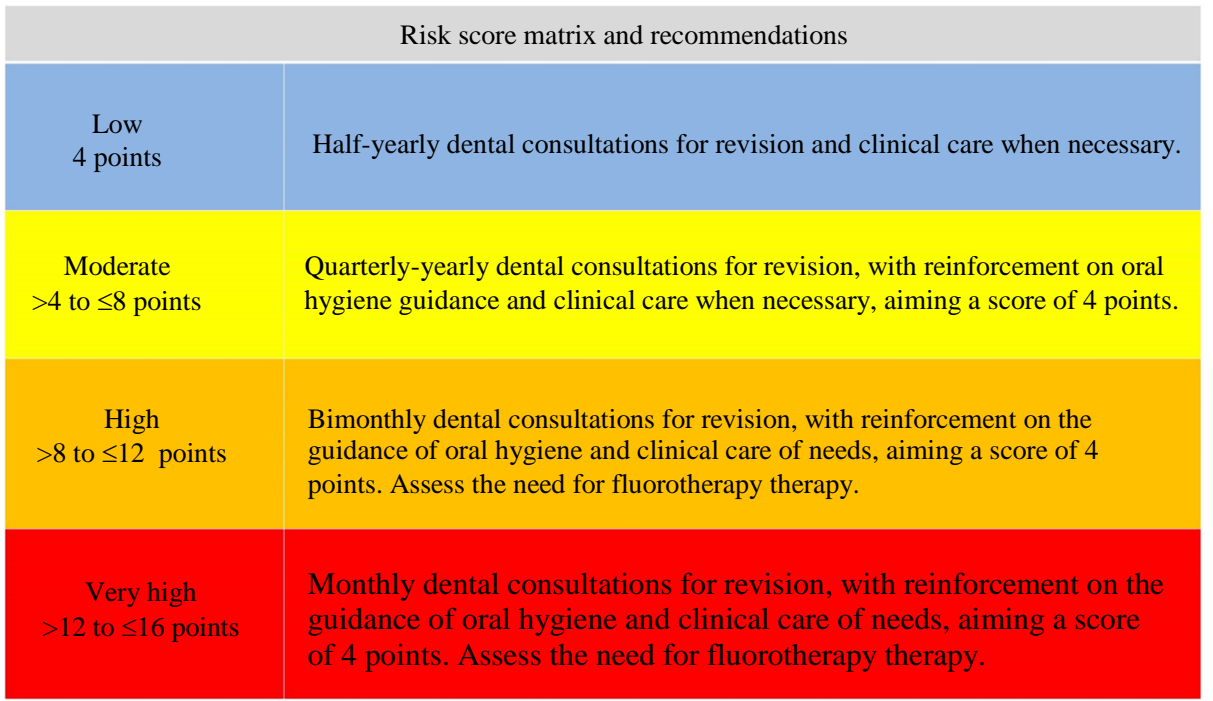

Fig. 5: Risk score matrix and recommendations. The sum of the matrix results provides a score that will indicate the individual's estimated risk for oral diseases. In each category (low, moderate, high and very high) there is a recommendation, which can be followed, to help control the patient

\section{Conclusion}

An adequate athlete's oral examination as a routine would allow the dental surgeon to determine basic oral health, hygiene quality and the overall susceptibility to risk factors for oral diseases. The definition of this oral profile, together with the individual needs of the athlete, can optimize treatment and prevention programs, including education in oral health. Based on this examination, the dentist can assist the sports nutritionist in making decisions and applying nutritional guidelines. Furthermore, such an examination allows decision-making with the fitness coach, assisting in exercise planning considering oral health status, which can affect performance. This instrument can be used as an aid in the diagnosis of the risk profile for odontogenic diseases in athletes. Future studies in sports dentistry can bring benefits to the oral health of athletes.

\section{Acknowledgement}

We have no thanks. The work was carried out exclusively by the authors, without other extermal support.

\section{Ethics}

The research was undertaken with the understanding and written consent of each participant and according to the ethical principles.

\section{Author's Contributions}

Bárbara Capitanio de Souza and Bruno Costa Teixeira: Study conception and design; Acquisition of data; Analysis and interpretation of data.
Randhall Bruce Carteri and André Luiz Lopes: Drafting of manuscript; Critical revision.

\section{References}

Anttonen, V., Kemppainen, A., Niinimaa, A., Pesonen, P., Tjäderhane, L., \& Jaana, L. (2014). Dietary and oral hygiene habits of active athletes and adolescents attending ordinary junior high schools. International Journal of Paediatric Dentistry, 24(5), 358-366. https://doi.org/10.1111/ipd.12078

Ashley, P., Di Iorio, A., Cole, E., Tanday, A., \& Needleman, I. (2015). Oral health of elite athletes and association with performance: A systematic review. British Journal of Sports Medicine, 49(1), 14-19. https://doi.org/10.1136/bjsports-2014093617

Azodo, C. C., \& Osazuwa, O. (2013). Dental conditions among competitive university athletes in Nigeria. Odonto-stomatologie tropicale $=$ Tropical dental journal, 36(141), 34-42. https://europepmc.org/article/med/23781684

Baishya, B., Satpathy, A., Nayak, R., \& Mohanty, R. (2019). Oral hygiene status, oral hygiene practices and periodontal health of brick kiln workers of Odisha. Journal of Indian Society of Periodontology, 23(2), 163. https://doi.org/10.4103/jisp.jisp_383_18

Broad, E. M., \& Rye, L. A. (2015). Do current sports nutrition guidelines conflict with good oral health. Gen Dent, 63(6), 18-23. 
Bryant, S., McLaughlin, K., Morgaine, K., \& Drummond, B. (2011). Elite athletes and oral health. International Journal of Sports Medicine, 32(09), 720-724. https://doi.org/10.1055/s-0031-1277192

Cassepp-Borges, V., Balbinotti, M. A., \& Teodoro, M. L. (2010). Tradução e validação de conteúdo: uma proposta para a adaptação de instrumentos. Instrumentação psicológica: Fundamentos e Práticas, 506-520.

Coombes, J. S. (2005). Sports drinks and dental. American Journal of Dentistry, 18(2), 101-104.

Cullinan, M. P., \& Seymour, G. J. (2013). Periodontal disease and systemic illness: will the evidence ever be enough?. Periodontology 2000, 62(1), 271-286. https://doi.org/10.1111/prd.12007

de Souza, B. C., Matte, B. F., Lopes, A. L., Teixeira, B. C., \& Lamers, M. L. (2020). Periodontal disease impairs muscle recovery by modulating the recruitment of leukocytes. Inflammation, 43(1), 382-391. https://doi.org/10.21037/jtd.2017.05.81

Divisi, D., Di Leonardo, G., Zaccagna, G., \& Crisci, R. (2017). Basic statistics with Microsoft Excel: a review. Journal of Thoracic Disease, 9(6), 1734.

Durham, W. J., Dillon, E. L., \& Sheffield-Moore, M. (2009). Inflammatory burden and amino acid metabolism in cancer cachexia. Current opinion in clinical nutrition and metabolic care, 12(1), 72. https://doi.org/10.1097/MCO.0b013e32831cef61

Frese, C., Frese, F., Kuhlmann, S., Saure, D., Reljic, D., Staehle, H. J., \& Wolff, D. (2015). Effect of endurance training on dental erosion, caries and saliva. Scandinavian Journal of Medicine \& Science in Sports, 25(3), e319-e326. https://doi.org/10.1111/sms.12266

Frese, C., Wohlrab, T., Sheng, L., Kieser, M., Krisam, J., Frese, F., \& Wolff, D. (2018). Clinical management and prevention of dental caries in athletes: A fouryear randomized controlled clinical trial. Scientific Reports, 8(1), 1-10. https://doi.org/10.1038/s41598018-34777-X

Gallagher, J., Ashley, P., Petrie, A., \& Needleman, I. (2018). Oral health and performance impacts in elite and professional athletes. Community Dentistry and Oral Epidemiology, 46(6), 563-568. https://doi.org/10.1111/cdoe.12392

Gallagher, J., Ashley, P., Petrie, A., \& Needleman, I. (2019). Oral health-related behaviours reported by elite and professional athletes. British Dental Journal, 227(4), 276-280. https://doi.org/10.1038/s41415-019-0617-8

Gottems, LBD, Carvalho, EMPD, Guilhem, D., \& Pires, MRGM (2018). Good practices in normal delivery: analysis of the reliability of an instrument by Cronbach's Alpha. Latin American Journal of Nursing, https://doi.org/10.1590/1518-8345.2234.3000
Head, D., Devine, D. A., \& Marsh, P. D. (2017). In silico modelling to differentiate the contribution of sugar frequency versus total amount in driving biofilm dysbiosis in dental caries. Scientific Reports, 7(1), 1-10. https://doi.org/10.1038/s41598-017-17660-Z

Hong, J., Whelton, H., Douglas, G., \& Kang, J. (2018). Consumption frequency of added sugars and UK children's dental caries. Community Dentistry and Oral Epidemiology, 46(5), 457-464. https://doi.org/10.1111/cdoe.12413

Landis, J. R., \& Koch, G. G. (1977). The measurement of observer agreement for categorical data. Biometrics, 159-174. https://doi.org/10.2307/2529310

Lönn, J., Ljunggren, S., Klarström-Engström, K., Demirel, I., Bengtsson, T., \& Karlsson, H. (2018). Lipoprotein modifications by gingipains of Porphyromonas gingivalis. Journal of Periodontal Research, 53(3), 403-413. https://doi.org/10.1111/jre.12527

Mathew, T., Casamassimo, P. S., \& Hayes, J. R. (2002). Relationship between sports drinks and dental erosion in 304 university athletes in Columbus, Ohio, USA. Caries Research, 36(4), 281-287. https://doi.org/10.1159/000063927

Minty, M., Canceill, T., Lê, S., Dubois, P., Amestoy, O., Loubieres, P.,.. \& Blasco-Baque, V. (2018). Oral health and microbiota status in professional rugby players: A case-control study. Journal of Dentistry, 79, 53-60. https://doi.org/10.1016/j.jdent.2018.10.001

Morgan, M. Z., Fairchild, R., \& Broughton, D. J. (2016). A survey of sports drinks consumption amongst adolescents. British Dental Journal, 220, 639-643. https://doi.org/10.1038/sj.bdj.2016.449

Mukaka, M. M. (2012). A guide to appropriate use of correlation coefficient in medical research. Malawi Medical Journal, 24(3), 69-71. https://www.ajol.info/index.php/mmj/article/view/8 1576

Murtaza, N., Burke, L. M., Vlahovich, N., Charlesson, B., O’Neill, H. M., Ross, M. L.,... \& Morrison, M. (2019). Analysis of the effects of dietary pattern on the oral microbiome of elite endurance athletes. Nutrients, 11(3), 614. https://doi.org/10.3390/nu11030614

Needleman, I., Ashley, P., Fairbrother, T., Fine, P., Gallagher, J., Kings, D.,... \& Naylor, M. (2018). Nutrition and oral health in sport: Time for action. https://doi.org/10.1136/bjsports-2017-098919

Needleman, I., Ashley, P., Fine, P., Haddad, F., Loosemore, M., De Medici, A.,... \& Porter, S. (2014). Consensus statement: Oral health and elite sport performance. British Dental Journal, 217(10), 587-590. https://doi.org/10.1038/sj.bdj.2014.1000 
Needleman, I., Ashley, P., Petrie, A., Fortune, F., Turner, W., Jones, J.,... \& Porter, S. (2013). Oral health and impact on performance of athletes participating in the London 2012 Olympic Games: A cross-sectional study. British Journal of Sports Medicine, 47(16), 1054-1058. https://doi.org/10.1136/bjsports-2013-092891

Noble, W. H., Donovan, T. E., \& Geissberger, M. (2011). Sports drinks and dental erosion. Journal of the California Dental Association, 39(4), 233-238. https://europepmc.org/article/med/21675676

Obregón-Rodríguez, N., Fernández-Riveiro, P., Piñeiro-Lamas, M., Smyth-Chamosa, E., MontesMartínez, A., \& Suárez-Cunqueiro, M. M. (2019). Prevalence and caries-related risk factors in schoolchildren of 12-and 15-year-old: A crosssectional study. BMC Oral Health, 19(1), 1-11. https://doi.org/10.1186/s12903-019-0806-5

Olczak-Kowalczyk, D., Turska, A., Gozdowski, D., \& Kaczmarek, U. (2016). Dental Caries Level and Sugar Consumption in 12-Year-Old Children from Poland. Advances in clinical and experimental medicine: Official organ Wroclaw Medical University, 25(3), 545-550. https://doi.org/10.17219/acem/61615

Ostrowska, A., Szymański, W., Kołodziejczyk, Ł., \& Bołtacz-Rzepkowska, E. (2016). Evaluation of the erosive potential of selected isotonic drinks: in vitro studies. Advances in Clinical and Experimental Medicine, 25(6), https://doi.org/10.17219/acem/62323
Sirimaharaj, V., Messer, L. B., \& Morgan, M. V. (2002). Acidic diet and dental erosion among athletes. Australian Dental Journal, 47(3), 228-236. https://doi.org/10.1111/j.1834-7819.2002.tb00334.X

Studen-Pavlovich, D., Bonci, L., \& Etzel, K. R. (2000). Dental implications of nutritional factors in young athletes. Dental Clinics of North America, 44(1), 161-78.

Touger-Decker, R., \& van Loveren, C. (2003). Sugars and dental caries. The American Journal of Clinical Nutrition, 78(4), 881S-892S. https://doi.org/10.1093/ajcn/78.4.881S

Valerio, A., Cardile, A., Cozzi, V., Bracale, R., Tedesco, L., Pisconti, A.,... \& Nisoli, E. (2006). TNF- $\alpha$ downregulates eNOS expression and mitochondrial biogenesis in fat and muscle of obese rodents. The Journal of Clinical Investigation, $\quad$ 116(10), 2791-2798. https://doi.org/10.1172/JCI28570

Varma, V., Yao-Borengasser, A., Rasouli, N., Nolen, G. T., Phanavanh, B., Starks, T.,... \& Peterson, C. A. (2009). Muscle inflammatory response and insulin resistance: Synergistic interaction between macrophages and fatty acids leads to impaired insulin action. American Journal of PhysiologyEndocrinology and Metabolism. https://doi.org/10.1152/ajpendo.90885.2008

\section{Supplementary Material}

- Characterization of the most frequent oral diseases in athletes with data from the literature

- Identification of risk factors for oral diseases

- Literature data collection

- Definition of frequency and quantities

- Risk analysis

- Estimation of the degree of probability and severity

- Risk matrix application

- Determination of the degree of risk

- Risk reduction strategies

- Prevention measures

- Disease control and treatment

- Maintenance and monitoring

Supplementary File 1: Organization chart for the construction of risk matrices 


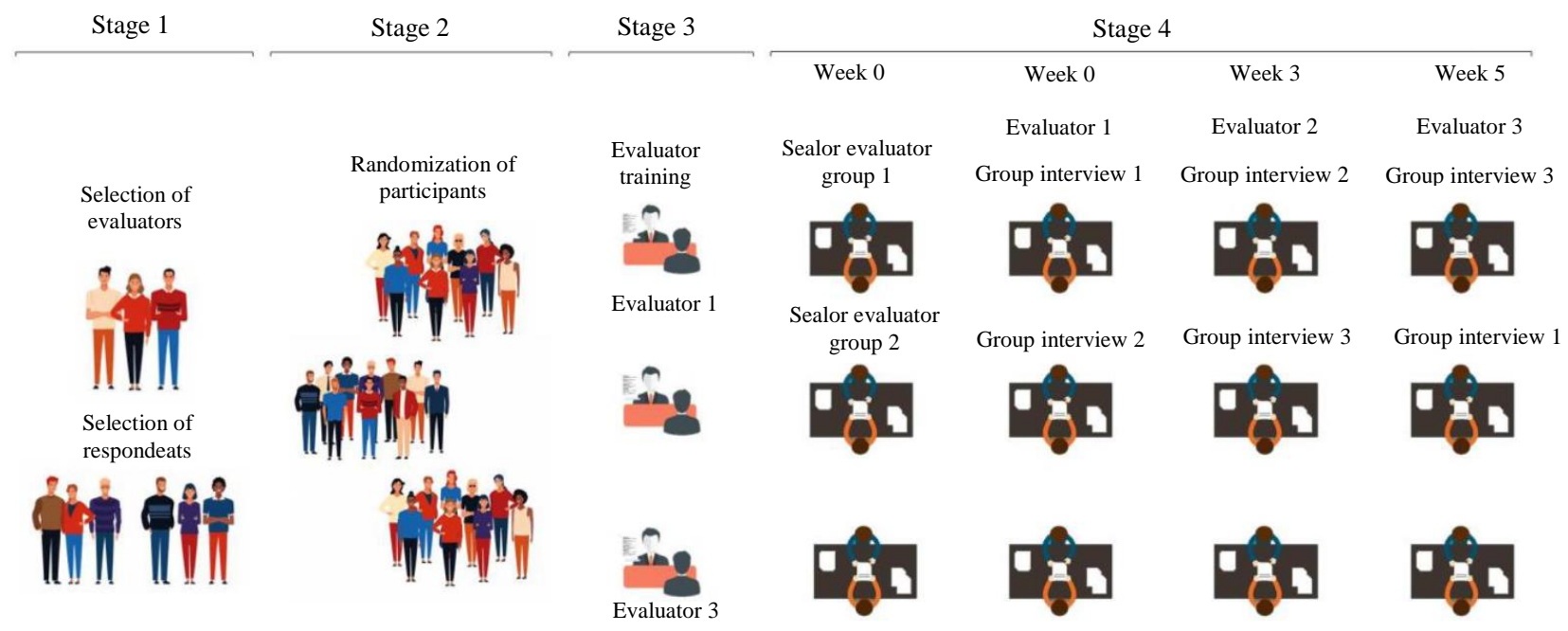

Supplementary File 2: Representation of the final stage of validation of risk matrices. Stage 1: Selection of evaluators and interviewees; Stage 2: Sample randomization; Stage 3: Training of evaluators; Stage 4: Application of risk matrices 